\title{
Discussion to the paper by J. J. Misiewicz
}

\section{Chairman: Dr Geoffrey Watkinson}

Chairman. One seems to see a number of patients with irritable colon who continue to have severe colicky abdominal pain despite a battery of modern antispasmodics. Have you had any of these?

Misiewicz. Yes we have. I studied a surgeon who developed spasm after gastrectomy. I think Dr Avery Jones said yesterday he taught himself to inject himself with propantheline subcutaneously about $20 \mathrm{~min}$ before a meal, hoping that this would quieten down his gut so that he would have his meal in comfort. This worked perfectly for about 6 weeks and then for some reason it stopped working, and he's back where he started I'm afraid, just getting one meal at night; he still injects himself in the evening, before that meal, and I think this gives him some pleasure but little relief.

HADLEY. Could I ask whether it is possible to control the motor activities of the colon with oral probanthine?

Misiewicz. This is something on which we have no objective evidence. It is very much easier to demonstrate the effect of all these drugs if one gives them parenterally, intravenously or intramuscularly. It is much more difficult to demonstrate the effect of any medication objectively when it is given in the ordinary course of treatment. We are now looking into this at the moment and I think if one wants to demonstrate an effect one has to use transit studies with radio-opaque shapes. This may prove useful in showing drug effects and have shown very striking changes in transit after medication with saline sodium phosphatase. I think these intraluminal pressures are too crude to pick up the changes, because the changes are fairly subtle ones.

WEIR. Is there a difference between Mebaverine and Probanthine?

MisIEWICZ. The manufacturers of Mabeverine think so. I think there are some pharmacological differences as well. I think Mabeverine is in the process of being clinically evaluated now in several centres and we should be hearing more about it.

Chairman. Could you say, if there is any future in the computer analysis of these records? It would be nice if we could play these things through a computer and get the answer, or refer them to some central computer who could analyse them for us.

MisIEwICZ. I think this is certainly a problem. Once you have made your record it is a terrible sweat to analyse it, because you have to do it by measuring up each wave, by hand with a ruler and pencil. We are trying to develop a method of computer analysis, which is in fact now working, which cuts down the time required and the labour required for extracting numerical data from these special wiggles. Now that this is working we hope to be able to establish some range of normal which is very wide, and then perhaps we can move on to some sort of diagnostic index for irritable bowet syndrome.

FleTCHER. Have any 5-HT antagonists been used for the relief of pain?

Misiewicz. One is a little bit scared of using 5-HT antagonists in people who don't absolutely require them because there are side effects from them which can be quite serious, so we have not used them for anyone with well, the belly-ache.

Question. Do you consider scleroderma to be an entity and can motility studies help with its diagnosis?

Misiewicz. Yes they can. Scleroderma does destroy gastrointestinal smooth muscle and most of the early changes will be in the gullet which becomes aperistaltic and enables a diagnosis to be made. 